\title{
A Experiência de Alunos de uma Escola Indígena nos Primeiros Contatos com Jogos Digitais de Matemática
}

\section{Clodis Boscarioli ${ }^{1}$, Márcia Regina Kaminski ${ }^{2}$, Maiara Aline Junkerfeurbom ${ }^{3}$, Rhuan Guilherme Tardo Ribeiro ${ }^{4}$}

${ }^{1}$ Universidade Estadual do Oeste do Paraná - UNIOESTE. Rua Universitária, 2069 Bairro Faculdade, CEP: 85819-110 - Cascavel - PR - Brasil

${ }^{2}$ Escola Municipal Aloys João Mann - Rua Salgado Filho, 3533 - Bairro Cancelli, CEP 85811-100 - Cascavel - PR - Brasil

${ }^{3}$ Sociedade Filantrópica Semear - Rua Mario Lorenzoni, 71 - Bairro Belo Horizonte, CEP 85884-000 - Medianeira - PR - Brasil

${ }^{4}$ Colégio Estadual Indígena Teko Nemoingo - Aldeia Indígena Tekoha Ocoy - Santa Rosa do Ocoy- S/N - CEP 85877-000 - São Miguel do Iguaçu - PR - Brasil

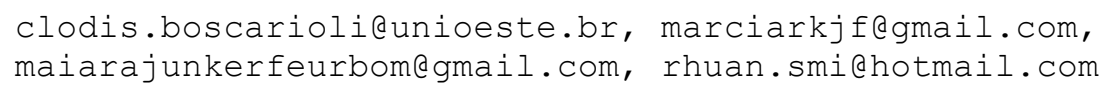

\begin{abstract}
Considering the contributions of the integration of digital games in the processes of teaching and learning in all contexts of teaching - whether urban, rural or indigenous school - this paper aims to describe the experience of using two digital games in Mathematics classes with the Students of the 6th year of the Teko Nemoingo Indigenous State College of the Tekoha Ocoy Indigenous Village in the municipality of São Miguel do Iguaçu/PR. The games were applied in a class of 20 students to approach the contents of Problem Solving and Fractions. It is perceived that in a playful and attractive way the games can serve as stimulus and subsidies for a better understanding of the contents.
\end{abstract}

Resumo. Considerando as contribuições da integração de jogos digitais nos processos de ensino e aprendizagem em todos os contextos de ensino - seja escola urbana, rural ou indígena - este trabalho tem por objetivo descrever a experiência de utilização de dois jogos digitais em aulas de Matemática com os alunos do $6^{\circ}$ ano do Colégio Estadual Indígena Teko Nemoingo da Aldeia Indígena Tekoha Ocoy - no município de São Miguel do Iguaçu/PR. Os jogos foram aplicados em uma turma composta por 20 alunos, para abordagem dos conteúdos de Resolução de Problemas e Frações. Percebeu-se que de forma lúdica e atrativa os jogos podem servir de estímulo e subsídios para melhor compreensão dos conteúdos.

\section{Introdução}

O objetivo principal de qualquer atividade de ensino é que a aprendizagem ocorra e seja significativa. Conforme destacado por Pelizzari et al. (2001), para atingir este objetivo é importante que os estudantes estabeleçam conexões entre seus conhecimentos prévios com os novos conhecimentos que lhe são apresentados, e que estejam motivados a aprender. Práticas pedagógicas que estejam ligadas à realidade dos alunos com as 
Tecnologias Digitais de Informação e Comunicação (TDIC) podem contribuir nesse aspecto motivacional em sala de aula. Segundo Petla (2008), as tecnologias devem estar presentes nas escolas, pois enriquecem o processo de construção do conhecimento.

Escolas com realidades específicas como as indígenas também devem inserir a tecnologia em suas práticas pedagógicas. Segundo Costa (2010), a tecnologia é um elemento global que foi incorporado à cultura indígena. Santiago (2014) também destaca que dispositivos eletrônicos são parte do dia a dia em muitas comunidades indígenas. Clarindo e Barboza (2010) salientam que embora sejam pouco utilizadas neste contexto, as tecnologias são instrumentos que podem contribuir muito com a Educação Indígena e representam um avanço necessário na qualidade da educação destes grupos, afirmando que "luta-se para proporcionar a garantia constitucional da informática na Educação Escolar Indígena" (Clarindo e Barboza, 2010, p. 1).

Dentre as diversas possibilidades de trabalho com as TDIC no ambiente escolar, o trabalho com jogos digitais pode trazer importantes contribuições no que diz respeito à aprendizagem lúdica, estimulante e desafiadora. "Os jogos criam uma necessidade convincente para saber, uma necessidade de perguntar, examinar, assimilar e dominar certas habilidades e conteúdos" (Silva e Queiroz, 2014, p.87). É possível enriquecer um conteúdo pela aplicação de jogos digitais contribuindo para manter a atenção, desafiando o aprendizado e estimulando o raciocínio.

Este artigo relata a experiência de utilização de dois jogos digitais em aulas de Matemática com alunos do $6^{\circ}$ ano do Colégio Estadual Indígena Teko Ñemoingo da Aldeia Tekoha Ocoy - Santa Rosa do Ocoy no município de São Miguel do Iguaçu/PR Os jogos foram aplicados na abordagem dos conteúdos Interpretação e resolução de situações problemas envolvendo as quatro operações (adição, subtração, multiplicação e divisão) e leitura e interpretação de frações simples.

Este artigo segue assim organizado: A Seção 2 discute a contribuição dos jogos digitais especialmente no ensino da Matemática; na Seção 3 a experiência realizada no colégio é descrita, a Seção 4 discute os resultados obtidos, e na Seção 5 estão as conclusões e perspectivas desse trabalho.

\section{Jogos Digitais como ferramentas de apoio ao ensino}

Dentre os diversos recursos tecnológicos existentes para apoiar os processos de ensino e aprendizagem, os jogos digitais são frequentemente utilizados, uma vez que propõem que os estudantes enfrentem desafios em um contexto diferente, mais estimulante do que com materiais tradicionais. Segundo Ilha e Cruz (2006), o jogo proporciona, que o indivíduo desenvolva seu conhecimento através da investigação, exploração, resolução de desafios em um contexto de diversão mais estimulante para o aprendizado.

Muitos jogos estão disponíveis em repositórios para a abordagem de conteúdos de diversas áreas e podem contribuir de forma relevante ao ensino. Para Araújo et al. (2013), os jogos digitais auxiliam no entendimento dos conteúdos e no desenvolvimento de estratégias, além de estimular o pensamento independente contribuindo para a construção do pensamento lógico matemático. A motivação, a aprendizagem por descoberta e a socialização são apontados como contribuições importantes dos jogos digitais para o ensino na Matemática. Segundo Araujo et al. (2016), se bem selecionados e analisados com critério pelo professor o jogo com a finalidade pedagógica - que não apenas diverte, mas aborda algum conteúdo e tem foco em algum 
objetivo de aprendizagem, pode ser uma ferramenta importante para auxiliar na investigação e na descoberta pelos alunos. Os autores apontam que os jogos podem enfatizar um aspecto fundamental da disciplina que é a experimentação, e podem tornar o ensino mais atraente aos estudantes.

Vários trabalhos são encontrados no sentido de selecionar, analisar e agrupar jogos digitais matemáticos para serem utilizados por professores nos diversos níveis de ensino. A exemplo disso, Araujo et al. (2016) catalogaram diversos recursos educacionais abertos e gratuitos que podem favorecer o ensino de vários conteúdos de Matemática para serem utilizados com o objetivo de tornar seu ensino mais compreensível e estimulante.

Outros trabalhos de utilização destes recursos têm sido relatados. Costa et al. (2009) desenvolveram um trabalho com alunos do curso de licenciatura em Matemática, da Universidade Federal do Rio Grande do Sul, no sentido de abordar o conteúdo de Geometria utilizando softwares e jogos matemáticos. Segundo os autores, por meio destes jogos foi possível que os alunos compreendessem o conteúdo de forma mais natural sem precisar decorar, entendendo os conceitos. Gonçalves (2011) relata a utilização de quatro jogos digitais para o ensino de Matemática com alunos da $8^{\mathrm{a}}$ série da rede estadual de Santa Catarina, destacando que o trabalho com jogos auxiliou na compreensão dos conteúdos, motivou os estudantes e aumentou a confiança em relação à capacidade de aprender Matemática. Couto et al. (2016), relatam uma experiência positiva com alunos do $4^{\circ}$ Ano do Ensino Fundamental I, de uma escola pública em Belém do Pará, na qual foi realizado um trabalho com o jogo TuxMath para o ensino da operação de adição, mostrando que o jogo auxiliou na aprendizagem lúdica e motivou os alunos durante as aulas.

O trabalho ora relatado se diferencia dos demais por relatar a experiência com jogos digitais no ensino de Matemática com alunos de $6^{\circ}$ ano do Ensino Fundamental II de uma escola indígena onde o uso de recursos tecnológicos é ainda pouco explorado.

\section{Métodos: Usando jogos no ensino da Matemática}

O Colégio Estadual Indígena Teko Ñemoingo da Aldeia Tekoha Ocoy atende atualmente em média 350 alunos entre Ensino Fundamental II, Ensino Médio e Ensino de Jovens e Adultos. A população é considerada de classe média-baixa. A infraestrutura atende adequadamente a esse público, embora os recursos tecnológicos sejam limitados e o acesso à internet nem sempre funcione devidamente. Existem apenas três computadores em funcionamento, de uso restrito dos professores. Fora da escola, de modo geral na comunidade, muitos alunos possuem computadores e celulares.

Considerando a necessidade de aliar recursos estimulantes como os jogos digitais aos processos de ensino e aprendizagem, buscou-se uma alternativa possível para aplicação de dois jogos digitais como complemento pedagógico na abordagem de dois conteúdos da disciplina de Matemática. O trabalho ora descrito foi realizado em uma turma de $6^{\circ}$ ano, composta por 20 alunos com idade entre 10 e 12 anos.

Em função da inexistência de um Laboratório de Informática para uso dos alunos, os professores pesquisadores levaram para a aula os seus notebooks pessoais. Assim, a aula foi aplicada com três notebooks nos quais os jogos foram previamente instalados, e diante da impossibilidade de todos utilizarem o computador simultaneamente, foram preparadas atividades impressas sobre o mesmo conteúdo, de 
VI Congresso Brasileiro de Informática na Educação (CBIE 2017)

Anais do XXIII Workshop de Informática na Escola (WIE 2017)

modo que, enquanto a maior parte da turma desenvolvia a atividade proposta de forma impressa, três alunos trabalhavam com os notebooks, em sistema de rodízio.

Para definição dos conteúdos abordados levou-se em consideração o currículo escolar, o planejamento e a necessidade de compreensão desses conteúdos pelos estudantes. Por estas razões foram escolhidos os conteúdos de Interpretação e resolução de situações problemas envolvendo as quatro operações básicas (adição, subtração, multiplicação e divisão) e Frações (numerador, denominador, representação).

O segundo passo foi a seleção dos jogos. De acordo com Prieto et al. (2005) um software que será utilizado pedagogicamente deve estar alinhado à intencionalidade do professor, ao conteúdo curricular e à realidade na qual será aplicado. Neste sentido, foi necessário buscar softwares que propusessem desafios adequados aos alunos em nível de complexidade, que fossem distribuídos gratuitamente e que permitissem o trabalho de forma offline, devido à ausência de acesso à internet. Os jogos foram escolhidos após serem avaliados segundo os critérios descritos em Backes e Maciel (2013), que estruturam a avaliação de objetos digitais de aprendizagem em quatro categorias, sendo que cada uma delas, aborda a avaliação de vários elementos. As categorias são definidas como: Categoria Psicopedagógica (motivação e atenção, nível de dificuldade), Categoria Didático-Curricular (contexto, objetivo pedagógico, conteúdo curricular, atividades), Categoria Layout de Interface (texto, imagem, animação, som), Categoria Layout de Navegação (página inicial, navegabilidade).

Para o conteúdo interpretação e resolução de situações problemas foi escolhido o jogo "Operações com números em situações problemas", desenvolvido por Alves (2015), constituído basicamente por uma plataforma onde os alunos devem guiar o personagem pelo ambiente capturando bandeiras que contém situações problemas. Ao responder corretamente o aluno ganha a bandeira em questão e pode continuar jogando. O jogo termina quando todas as bandeiras forem capturadas. Os problemas são aleatórios e de diferentes níveis de complexidade.

Para o conteúdo Frações foi selecionado o Game das frações, desenvolvido por Alves (2016), composto por três mini jogos: Labirinto das Frações, um jogo de labirinto onde o aluno deve percorrer e capturar cones com representações de frações e escrever por extenso corretamente qual é a fração representada; Acerte o alvo, jogo de identificar a fração e sua leitura correta acertando no alvo indicado; e Porcentagem das frações, jogo onde o aluno deve guiar o personagem por um labirinto e responder questões relacionando frações com porcentagens. Neste trabalho, foi utilizado apenas o Labirinto das frações em função do tempo disponível e do número restrito de equipamentos.

A Figura 1 exemplifica algumas telas dos jogos utilizados. Sobre o jogo "Operações com números em situações problemas", na Figura 1(a) está a tela inicial do jogo onde constam as instruções. A Figura 1(b) mostra a tela com o ambiente inicial do jogo no qual o aluno deverá guiar o personagem fugindo dos obstáculos e ao mesmo tempo capturar as bandeiras. A Figura 1(c) retrata um exemplo de um problema que é exibido quando o aluno encosta na bandeira que deseja capturar. As telas do Game das frações são também exemplificadas. A Figura 1(d) apresenta a tela inicial do jogo. Clicando sobre o botão com a letra "i" no canto inferior direito da tela o aluno pode ler as instruções para cada um dos seus minijogos, conforme exemplificado na Figura 1(e). A Figura 1(f) mostra a tela do Labirinto das Frações, onde o aluno deve guiar o jipe usando as setas direcionais até encontrar um cone. Quando encostar em um cone, uma 
VI Congresso Brasileiro de Informática na Educação (CBIE 2017)

Anais do XXIII Workshop de Informática na Escola (WIE 2017)

fração será apresentada no canto inferior esquerdo da tela e ele deve escrever por extenso dentro do retângulo azul a fração solicitada.

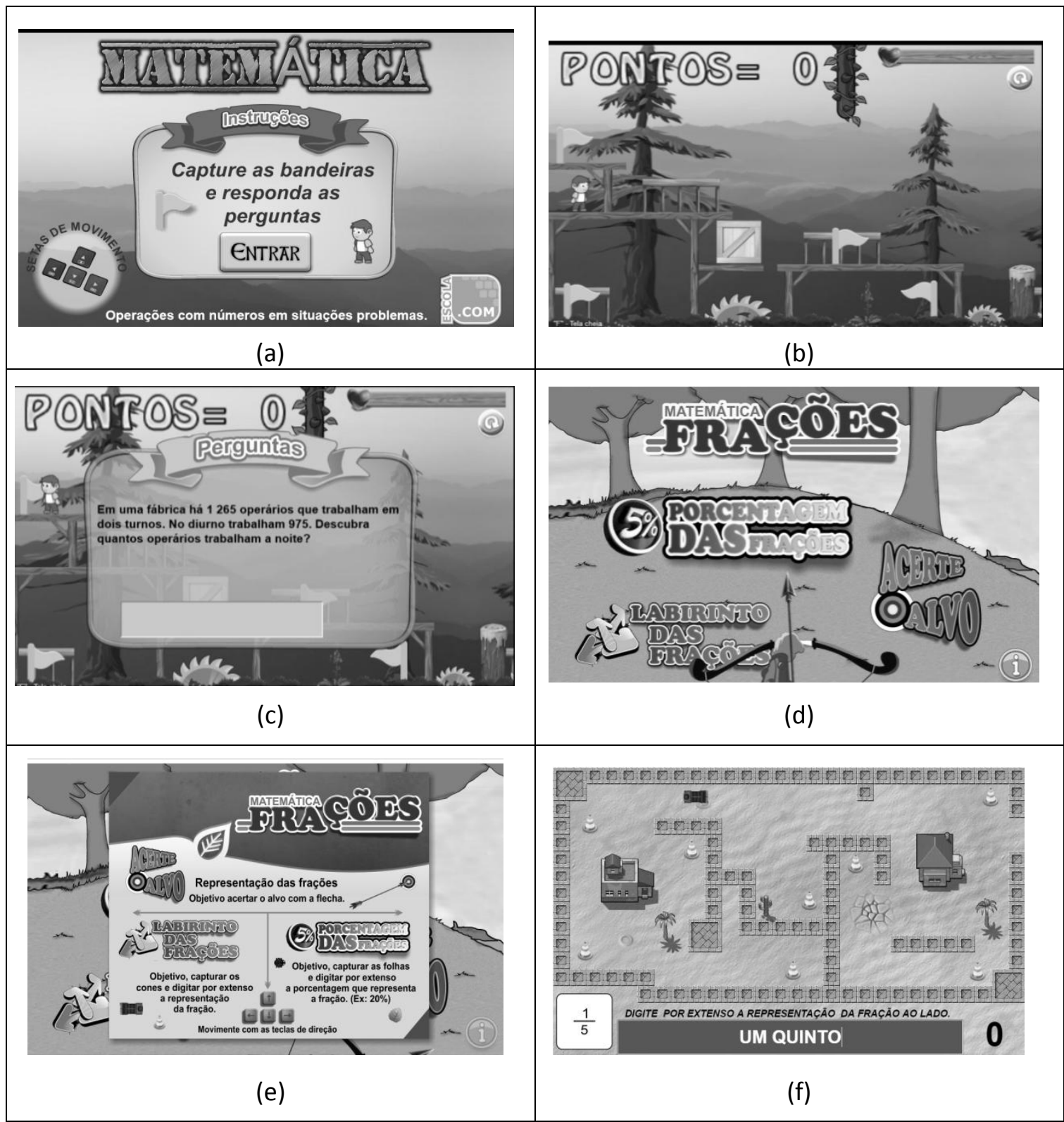

Figura 1. Exemplos de algumas telas dos jogos Operação com números em situações problemas e Game das Frações

Tanto o jogo Operações com números em situações problemas, como o jogo Game das frações, podem ser classificados como softwares de apoio pedagógico, na categoria jogos educativos, pois contribuem para o reforço dos conteúdos de forma lúdica. É necessário que o usuário tenha conhecimento do conteúdo em questão. Ambos os jogos se mostraram adequados ao contexto deste trabalho, estão disponíveis para download gratuitamente no repositório de objetos Educacionais da Secretaria de Educação do município de Cascavel/ PR, e podem ser instalados de forma simples nos Sistemas Operacionais Linux e Windows.

O trabalho foi desenvolvido no período de uma manhã, dividida para a aplicação dos dois conteúdos. O primeiro conteúdo abordado foi Interpretação e resolução de 
problemas, com foco na interpretação dos problemas e na identificação de quais das quatro operações básicas devem ser utilizadas para resolvê-los. Para a realização desta etapa, utilizou-se 2 horas/aula.

Explicou-se aos alunos que enquanto alguns desenvolveriam atividades impressas, três alunos de cada vez trabalhariam com os jogos digitais. O jogo foi apresentado com o auxílio do multimídia. Foi organizado o revezamento, coordenado pelos professores, para uso dos notebooks. A cada 15 minutos, os alunos trocavam de posições. Enquanto dois professores orientavam o maior grupo de alunos no desenvolvimento da atividade impressa, outro professor auxiliava os três alunos que faziam uso do jogo. Considerando o tempo disponível e o número restrito de computadores, o uso da calculadora foi permitido apenas para os alunos que estavam jogando. Foi ensinado aos alunos como trabalhar com a calculadora do computador.

Após 2 horas/aula de trabalho com este conteúdo houve intervalo. No retorno à sala de aula, foi dada continuidade aos trabalhos com o conteúdo Frações. As atividades impressas foram distribuídas e iniciou-se o revezamento para uso dos notebooks com o jogo Game das Frações. O funcionamento e as regras do jogo foram explicados com auxílio de projetor multimídia. Houve novamente um revezamento entre os alunos que utilizaram os jogos e o tempo de 15 minutos para cada rodada foi controlado pelos professores para que todos tivessem a oportunidade de jogar. Foram também utilizadas mais 2 horas/aula. Os alunos foram auxiliados pelos professores tanto nas dificuldades com o conteúdo como nas dificuldades com o software e nas atividades impressas.

As atividades impressas foram compostas por situações problemas semelhantes às apresentadas no jogo, porém elaboradas pelos professores pesquisadores. Assim como no jogo, os problemas envolviam conhecimentos das quatro operações básicas, sendo que uma mesma situação problema poderia envolver o uso de mais de uma operação. Em relação às atividades impressas do conteúdo frações, também elaboradas pelos autores, estas abordaram o reconhecimento das partes de uma fração, a identificação de frações em diferentes formas (por extenso, por representação geométrica ou ilustrativa, fracionária). O conteúdo das atividades impressas estava relacionado ao conteúdo dos jogos utilizados, de modo que o trabalho entre as duas atividades estava alinhado, com os mesmos objetivos, sendo, portanto, complementares. Os jogos digitais, foram assim utilizados, como mais um recurso pedagógico para abordagem diferenciada dos conteúdos matemáticos, proporcionando aos estudantes a possibilidade de vivenciar experiências pedagógicas com as tecnologias digitais.

\section{Resultados e Discussão}

O uso de jogos digitais para abordar conteúdos matemáticos contribuiu para o aumento do interesse dos alunos. Foi possível perceber que eles entenderam a necessidade de um revezamento organizado para uso do computador e respeitaram o tempo e a vez de cada colega. Apesar de esperarem pela sua vez de jogar com ansiedade, desenvolveram as atividades impressas sem reclamações e com interesse. Embora empolgados, não houve problemas de indisciplina e desenvolveram tanto as atividades impressas quanto no computador com bastante empenho. O número restrito de equipamentos não impediu a realização do trabalho, semelhante ao proposto por Garofalo (2017) no sentido de organizar a aula em estações de trabalho com atividades diferenciadas e dividir os alunos em equipes que passam por todas as estações em sistema de revezamento. Nesta 
proposta, os alunos desempenharam as atividades de cada estação em momentos diferentes coordenados e orientados pelo professor. Para essa autora, é uma possibilidade para uso de tecnologias quando a escola não dispõe de equipamentos para todos os alunos e para desenvolver habilidades como autonomia, organização, respeito e interação.

O uso do computador revelou que os alunos tinham conhecimentos limitados de Informática, pois apresentaram bastante dificuldade, por exemplo, em utilizar o mouse e o teclado. Porém, de modo geral, os estudantes logo compreenderam os passos dos jogos e familiarizam-se com os dispositivos de interação. Como foi permitido o uso da calculadora do computador para resolverem as operações foi necessário ensinar como usá-la. O fato de alguns sinais serem diferentes dos habituais, por exemplo, a multiplicação (*) e a divisão (/) também lhes foi uma novidade.

Pode-se afirmar que a dificuldade na interpretação dos problemas foi maior do que lidar com a tecnologia, o que lhes dificultou o avançar no jogo. Alguns fatores podem ter influenciado neste aspecto, como a dificuldade de compreender a língua portuguesa - na qual as situações problemas do jogo estavam escritas, visto que o idioma materno e mais utilizado pelos estudantes é o Guarani. Na oralidade, os alunos têm uma compreensão razoável da língua portuguesa, porém ler e interpretar o código escrito envolve processos complexos que podem ter dificultado a interpretação.

Outro fator que pode ter gerado dificuldades é o fato de os problemas propostos estarem fora da realidade contextual dos alunos. Segundo o professor regente da turma, em uma comunidade onde a cultura é o centro do processo escolar, as atividades e metodologias devem ser voltadas à realidade cotidiana dos estudantes, o que dificultou algumas interpretações durante os jogos e os exercícios propostos. Costa (2010) destaca a importância do alinhamento cultural na educação indígena e que as mídias tecnológicas não são adaptadas a estas comunidades. Esta situação aponta à necessidade de produções de softwares educacionais voltados para diferentes contextos culturais que atendam às especificidades das comunidades. Além disso, a dificuldade em relação à interpretação de problemas é algo comum em todas as realidades. Como alguns problemas envolviam mais de uma operação matemática, muitos alunos ficaram confusos na resolução.

Outro aspecto interessante foi que muitos alunos resolviam a operação na calculadora e quando clicavam no jogo para inserir o resultado, a calculadora era minimizada e eles esqueciam qual era o resultado. Alguns tinham dificuldade em retornar à calculadora sem auxílio. Talvez o uso da calculadora portátil tivesse sido mais produtivo no sentido de possibilitar que os alunos avançassem mais rapidamente nas fases do jogo. Por outro lado, a experiência de manipular dois softwares simultaneamente e usar uma calculadora virtual também foi uma aprendizagem extra.

Em média, durante os 15 minutos de jogo, os alunos conseguiram resolver três situações problemas. No total o jogo apresenta 20 bandeiras cada uma com um problema a ser resolvido. Infelizmente o tempo não permitiu que jogassem até o final, mas a experiência foi estimulante para os estudantes, que apesar das dificuldades, se esforçaram bastante para resolver as situações problemas apresentadas.

Frações, o segundo conteúdo trabalhado, estava sendo abordado pelo professor nas aulas de Matemática, o que facilitou o trabalho e os alunos apresentaram mais facilidade. Os alunos souberam responder as perguntas, mostrando domínio do 
conteúdo, e poucos alunos precisaram de ajuda em relação ao conteúdo. No jogo Labirinto das frações, quando precisavam escrever por extenso a fração, mais uma vez a dificuldade com o uso do computador foi diagnosticada na utilização do teclado para digitação, principalmente na inserção de acentos. Dificuldades com a escrita também apareceram neste momento. Erros de ortografia e concordância foram comuns. Apesar de identificarem e lerem corretamente a fração, não escreviam por extenso da forma correta, o que os impedia de continuar, pois o jogo só avança quando o aluno digita corretamente o resultado. Essa dificuldade com a escrita é compreensível em função dos desafios com o idioma. Foi necessário auxiliar na digitação dos acentos, dar espaço entre outras funções, explicando-lhes detalhes da língua portuguesa. Nesta atividade, houve uma aluna que não quis jogar. Tentou-se motivá-la e descobrir o motivo, mas ela não quis revelar, de forma que não se pode afirmar se ela não gostou dos jogos ou se o problema foi a dificuldade com o conteúdo ou com a manipulação dos equipamentos.

Os demais alunos todos jogaram e disseram ter gostado mais do segundo jogo, pois era "mais fácil" e que "queriam jogar mais". O fato de terem gostado mais deste segundo jogo, provavelmente está relacionado ao maior domínio do conteúdo em si, devido ao fato de estar sendo abordado nas aulas de Matemática, o que possibilitou o avanço mais significativo nas fases deste jogo.

Em relação aos softwares escolhidos, ambos funcionaram bem, sem apresentar problemas técnicos, atendendo satisfatoriamente o conteúdo e sendo atrativos aos alunos. Como observação, constatou-se que o jogo do Labirinto das Frações traz uma fração que representa "dez décimos", que é equivalente a um inteiro, porém o jogo só aceita como resposta a opção "dez décimos". Observou-se que a maior parte dos alunos digitava um inteiro e o jogo não aceitava como resposta correta, o que gerou dúvida nos alunos. Uma solução seria configurar as duas opções como possíveis respostas no jogo.

Percebeu-se durante as atividades que o uso dos jogos favoreceu o interesse dos alunos. Embora tenham sido ministradas 4 horas/aula sequenciais de Matemática eles não demonstraram cansaço ou insatisfação com as atividades. Pelo contrário, mostraram-se curiosos e motivados com o uso dos jogos.

Em relação ao conteúdo, notou-se que as dificuldades foram as mesmas tanto nas atividades impressas quanto nas desenvolvidas no computador, tanto nos exercícios com situações problemas, quanto no trabalho com frações. No entanto, o fato de trabalhar com uma ferramenta diferente estimulou os estudantes. Resolver um problema em um contexto de um jogo mostrou-se mais interessante do que no material impresso, embora as dificuldades com a interpretação e com as operações tenham sido as mesmas. $\mathrm{O}$ fato de ganhar pontos, enfrentar obstáculos e conduzir um personagem em uma plataforma torna mais desafiador resolver o problema de forma adequada. $\mathrm{O}$ desejo de acertar ficou evidente nos rostos dos alunos diante do computador. Esse desejo levou a uma maior atenção e maior empenho na busca pela solução do problema.

Em termos de desempenho nos jogos, percebeu-se que as dificuldades com o manuseio do equipamento não impediram os alunos de realizar as atividades e nem foram fatores desestimulantes. Pelo contrário, os alunos mostraram-se envolvidos e desejosos de vencer os desafios. Acredita-se também, observando o desempenho dos estudantes, que não seria necessário muito mais tempo para que eles ficassem mais familiarizados com a máquina e superassem suas dificuldades, o que a existência de um laboratório de informática na escola em muito ajudaria. 
VI Congresso Brasileiro de Informática na Educação (CBIE 2017)

Anais do XXIII Workshop de Informática na Escola (WIE 2017)

\section{Conclusões}

A formação dos alunos em um sistema escolar onde a tecnologia está inserida ajuda a fortalecer os conhecimentos prévios, estimular e desafiar os estudantes tornado o aprender mais prazeroso e significativo. Os jogos digitais pedagógicos promovem a desenvoltura do aluno durante seu processo de desenvolvimento intelectual. O trabalho revelou a importância da existência de um Laboratório de Informática à disposição dos alunos na escola indígena, pois estariam mais familiarizados às tecnologias, poderiam jogar simultaneamente e teriam avançado mais no desafio. Por outro lado, também mostrou que mesmo onde não existe Laboratório de Informática, é possível criar possibilidades de utilização das TDIC, ainda que de maneira restrita, como um diferencial metodológico para abordar certos conteúdos. Um trabalho ainda que com recursos limitados, onde não se tenha estrutura física adequada, pode trazer contribuições importantes ao ensino.

A experiência de uma aula diferente marcou significativamente os alunos desta escola ainda que não tenham usufruído plenamente os jogos como esperavam. Além disso, a necessidade de revezamento para uso do computador, também abre possibilidades de trabalhar aspectos importantes para o desenvolvimento da cidadania, como o respeito, o saber esperar, a organização e o compartilhar. Os recursos tecnológicos devem fazer parte do cotidiano escolar, e não apenas em atividades esporádicas. Os jogos foram adequados para os contextos em que foram trabalhados. Como possibilidade de um trabalho futuro, é possível a realização de oficinas em escolas vizinhas que possuam laboratório, onde os alunos possam ter a oportunidade de trabalhar mais com recursos tecnológicos e assim avançar em propostas mais elaboradas de uso pedagógico das TDIC. O trabalho também apontou a necessidade de softwares educacionais que sejam adequados e alinhados às diferentes culturas e que contemplem a diversidade cultural. Assim, uma pesquisa interessante também seria avaliar o que existe atualmente de material disponível neste sentido para a educação indígena e a possibilidade de desenvolvimento de materiais específicos para essas comunidades.

Apesar de terem sido abordados apenas dois conteúdos da disciplina de Matemática nesta experiência, muitos outros conteúdos podem ser explorados com diferentes tipos de jogos digitais. Muitos repositórios apresentam objetos digitais de aprendizagem, sendo possível aliar estes recursos a basicamente qualquer conteúdo ou área, sendo necessário apenas que o professor conheça os recursos, tenham clareza de seus objetivos e saiba utilizá-los pedagogicamente.

\section{Referências}

Alves, J. C. V. (2016). "Game das frações". Disponível em: <http://www.atividades.fundetec.org.br/>. Acesso em 01 mar.2017.

Alves, J. C. V. (2015). "Operações com números em situações problemas". Disponível em: <http://www.atividades.fundetec.org.br/>. Acesso em 01 mar.2017.

Araújo, A. K. L. Araújo, D. C. M. Alves, S. D. and Lins, A. F. (2013). "Jogos digitais na educação matemática". In: Encontro de Iniciação a Docência de UEPB. V ENID. Disponível em: < goo.gl/tQShhP >. Acesso em: 05 abr. 2017.

Araujo, J. N. F. L. Bezerra, A. R. F. Morais, C. G. B. and Gomes, A. F. (2016). "Um Catálogo de Recursos Educacionais Digitais (RED) Gratuitos de Matemática para 
VI Congresso Brasileiro de Informática na Educação (CBIE 2017)

Anais do XXIII Workshop de Informática na Escola (WIE 2017)

auxiliar os professores do Ensino Fundamental". In: 22a Workshop de Informática na Escola (WIE 2016), Uberlândia. p. 621-628.

Backes, E. M. and Maciel, C. (2013). "Objetos de aprendizagem, objetos educacionais, repositórios e critérios para a sua avaliação". In: Cristiano Maciel. (Org.). Educação a Distância: Ambientes Virtuais de Aprendizagem. 1ªed. Cuiabá-MT: UFMT, v.1, p. 159-196.

Clarindo, R. and Barboza, R. (2010). "Aplicando Educação: Informática aplicada à educação Indígena". Disponível em: < goo.gl/a3QINK >. Acesso em: 08 abr. 2017.

Costa, A. C. (2010). "A comunidade indígena e o mundo tecnológico: reflexões sobre os impactos das mídias sociais na vida dos Aikewára". In: Simpósio Hipertexto e Tecnologias na Educação, Anais. Pernambuco: UFP. p. 1-14. Disponível em: <goo.gl/WRHhKj >. Acesso em: 10 abr. 2017.

Costa, B. F. Jorge, M. O. Basso, M. V. A. and Tonet, V. G. (2009). "Interação Virtual para a aprendizagem de Matemática". In: $15^{\mathrm{a}}$ Workshop de Informática na Escola (WIE 2009), Anais. 2009. p. 1897-1900.

Couto, F. V. Sousa, D. F. Barreto W. D. L. and Sousa, A. M. C. (2016). "Contribuições da Informática Educativa para a Operação de Adição: Uma Experiência com Alunos nos Anos Iniciais". In: Anais do XXII Workshop de Informática na Escola. (WIE 2016), Anais. 2016. p. 171-180.

Garofalo, D. (2017). "Não temos um computador para cada aluno. E agora?". In: Nova Escola: Blog Tecnologia na Educação. Disponível em: 〈goo.gl/hr1qkF>. Acesso em: 29 jun. 2017.

Gonçalves, P. A. S. (2011). "Jogos digitais no ensino e aprendizagem da matemática: efeitos sobre a motivação e o desempenho dos alunos". Mestrado em Didática e Inovação no Ensino das Ciências (Matemática). UALG. Disponível em: < goo.gl/WskQeY> Acesso em: 08 abr. 2017.

Ilha, P. C. A. and Cruz, D. M. (2006). "Jogos eletrônicos na educação: uma pesquisa aplicada do uso do Sim City4 no ensino médio". In: Anais do XII Workshop de Informática na Escola. Campo Grande. p. 240-246.

Pelizzari, A. Kriegl, M. D. L. Baron, M. P. Finck, N. T. L. and Dorocinski, S. I. (2001). "Teoria da Aprendizagem Significativa Segundo Ausubel". Revista Pec, Curitiba, v. 2, n. 1, p. 37-42, Jul 2001.

Petla, R. J. (2008). "Geogebra - Possibilidades para o Ensino da Matemática". Unidade Didática. p. 2-44. Disponível em: < goo.gl/pF7EM3 > Acesso em: 20 de mar. 2017.

Prieto, L. M. Trevisan, M. C. B. Danesi, M. I. and Falkembach, G. A. M. (2005). "Uso das Tecnologias Digitais em Atividades Didáticas nas Séries Iniciais". Renote: revista novas tecnologias na educação, Porto Alegre, v. 3, n. 1, p. 1-11, maio. Disponível em: < goo.gl/s7i9JQ>. Acesso em: 10 de abr. de 2017.

Santiago, A. (2014). "Avanço da tecnologia em aldeia muda cotidiano de índios no Amapá". Disponível em: < goo.gl/ekTgcF >. Acesso em: 07 abr. 2017.

Silva, L. R. A. and Queiroz, R. J. G. B. (2014). "Aprendizagem baseada em jogos: Uma reflexão sobre o modelo de currículo da Quest to Learn". In: Anais do XX Workshop de Informática na Escola (WIE 2014), Dourados. p. 86-90. 